\title{
New-Generation Liquid Crystal Materials for Application in Infrared Region
}

\author{
Piotr Harmata * (D) and Jakub Herman (10 \\ Faculty of Advanced Technologies and Chemistry, Military University of Technology, 2 gen. S. Kaliskiego St., \\ 00-908 Warsaw, Poland; jakub.herman@wat.edu.pl \\ * Correspondence: piotr.harmata@wat.edu.pl
}

\section{check for}

updates

Citation: Harmata, P.; Herman, J. New-Generation Liquid Crystal Materials for Application in Infrared Region. Materials 2021, 14, 2616. https://doi.org/10.3390/ma14102616

Academic Editor: Antonio Polimeni

Received: 26 April 2021

Accepted: 13 May 2021

Published: 17 May 2021

Publisher's Note: MDPI stays neutral with regard to jurisdictional claims in published maps and institutional affiliations.

Copyright: (c) 2021 by the authors. Licensee MDPI, Basel, Switzerland. This article is an open access article distributed under the terms and conditions of the Creative Commons Attribution (CC BY) license (https:/ / creativecommons.org/licenses/by/ $4.0 /)$.

\begin{abstract}
This study presents 13 new organic compounds with self-assembling behavior, which can be divided into two groups. The first synthesized group includes compounds based on $4^{\prime}-$ (trifluoromethoxy)-[1,1'-biphenyl]-4-yl-4-(trifluoromethoxy) benzoate core, and the second includes compounds based on 4-((4-(trifluoromethoxy)phenyl)ethynyl)phenyl-4-(trifluoromethoxy) benzoate core. They differ in the number and location of the fluorine atom in the lateral position. Mesomorphic properties, phase transition enthalpies, refractive indices, birefringence, and MWIR (mid-wavelength infrared) spectral properties of the compounds were investigated, and the results were compared with currently used materials. The influence of the length of the core as well as type and position of substituents in the molecular core was analyzed. The lack of aliphatic protons in the molecular structure generated unique infrared properties.
\end{abstract}

Keywords: nematic; ester; fluorinated liquid crystal; infrared transparent material; cladding layer; fused silica waveguides

\section{Introduction}

The first thought that comes to mind at the mention of liquid crystals is the display industry [1-4], which has given them the greatest fame and recognition. It is not surprising as many items and devices of everyday use, such as monitors, TV sets, telephones, and smartwatches use these materials in the element designed for displaying information. Nevertheless, the application possibilities of liquid crystals (LC) go far beyond this area.

To better illustrate the breadth of this application, one should look at the spectrum of electromagnetic radiation. LCs are used in devices operating in visible light, infrared (IR) [5], millimeter wave [6-10], terahertz [11-14], and gigahertz [15-18].

In recent years, there has been an increased interest in the infrared range, in particular the MWIR (mid-wavelength infrared) range, where there are, among others, strategic communication bands $[19,20]$ and photonic sensors for military applications [21-26]. It is worth noting that liquid crystals have already been used in the MWIR range in Lyot filters [27], photonic crystal fibers [28,29], light shutters [30-32], adaptive optics [33], laser beam steering [34-36], and optical valves [37-39]. However, their use has been limited to areas where LCs do not absorb radiation, i.e., windows. To increase the applicability of LCs in the MWIR range, the approach to molecular design has to be changed.

The vast majority of rod-like LCs synthesized so far are compounds from the so-called classical approach of molecular design. It assumes that in order for a compound to exhibit liquid crystal properties, it must consist of a rigid core and appropriate substituents in the terminal and lateral positions. The most commonly used cores include derivatives of oligophenyls (e.g., terphenyl [40,41] and quaterphenyl [42]) and tolanes (e.g., phenyltolane [43-46] and bistolane [47]), which may also have other linking groups, e.g., ester and ether [48]. To obtain a suitable shape anisotropy, aliphatic chain(s) and/or strong dipole moment generating groups, such as cyano (CN) [49] and isothiocyanate (NCS) [50,51], are used as terminal substituents. Laterally unsubstituted molecules often fail to meet the 
required criteria for LCs, such as low melting point, relevant mesomorphic morphology (generally only the nematic phase is desirable), smectic suppression, appropriate clearing temperature, sign of dielectric anisotropy, and sufficiently high optical anisotropy. Therefore, a fluorine [52-54] or chlorine atom is most often introduced into the rigid core in the lateral position [55]. In some cases, it is necessary to use larger bulky substituents, such as short alkyl chains in the form of methyl $\mathrm{CH}_{3}$ or ethyl $\mathrm{C}_{2} \mathrm{H}_{5}$ groups, to achieve the required properties. Molecules designed in this way can be used in all the aforementioned electromagnetic radiation ranges, excluding infrared, in particular the MWIR range. For these wavelengths, these materials show strong absorption bands [56]. The first band $(\lambda \sim$ 3.0-3.5 $\mu \mathrm{m}$ ) is very wide and of strong intensity, which comes from the stretching vibrations of the $\mathrm{C}-\mathrm{H}$ bonds in the aromatic ring and the aliphatic chain. Another band is located at $\lambda \sim 4.5 \mu \mathrm{m}$ and is related to the stretching vibrations of $\mathrm{C} \equiv \mathrm{N}$ and $\mathrm{C} \equiv \mathrm{C}$ bonds. Moreover, the isothiocyanato (NCS) group has a strong and broad absorption band in the range of $\lambda$ $4.5-5.2 \mu \mathrm{m}$. The presence of these parasitic absorption bands has led to very limited use of liquid crystals in the MWIR range.

As part of our previous work [57-59], we developed a new molecular design approach that allowed us to obtain a next-generation self-assembling material primarily for use in the infrared range, and particularly in the MWIR range [60-63]. This approach involved shifting parasitic absorption bands toward longer wavelengths. Therefore, in the terminal positions of rod-like molecules, the use of short perfluorinated chains and/or a fluorine or chlorine atom was proposed. In the lateral positions, the use of a fluorine atom, a chlorine atom, or a trifluoromethoxy group was proposed. This approach allowed us to obtain compounds characterized by high transparency in the MWIR range. It is worth emphasizing that it is not possible to completely eliminate absorption bands in this area while maintaining the mesomorphic properties of the compound. Moreover, previous studies have shown that with such short perfluorinated chains, the core is mainly responsible for the presence of liquid crystalline phases. Therefore, in this study, we decided to investigate its derivatives and try to broaden knowledge of the structure-properties relationship in this particular area of LCs that is still new.

High content of fluorine atoms in the molecule may have additional benefits. Such materials have been found to be used as a potential overlayer or cladding layer on fused silica waveguides [64-66]. Thus, it is possible to minimize dissipation losses. In order to achieve this goal, the liquid crystal must have one or both major refractive indices lower than that of the waveguide layer. Although such LC materials are known to exist $[67,68]$, these compounds do not have conjugated ( $\pi$-delocalized) systems and therefore have very low birefringence values $(\Delta \mathrm{n} \approx 0.05)$. This study proposes a compound with a completely different structure that is rich in $\pi$-electrons, provides much higher birefringence, and meets the criteria for setting future waveguiding devices.

\section{Experimental}

\subsection{Materials}

1-Bromo-4-(trifluoromethoxy) benzene, 4-bromo-2-fluorophenol, 2-dicyclohexylphosphino-2' '6'-dimethoxybiphenyl (SPhos), 4-bromo-3-fluorophenol, 1-bromo-2-fluoro-4-(trifluoromethoxy) benzene, and oxone were purchased from Fluorochem (Hadfield, UK) and used as received. Magnesium for Grignard reactions (turnings), oxalyl chloride, 1,8diazabicyclo(5.4.0)undec-7-ene, and 2-methylbut-3-yn-2-ol were purchased from Acros Organics, (Geel, Belgium) and used as received. Toluene, acetone, hydrochloric acid, sodium nitrite, potassium iodide, anhydrous potassium carbonate, potassium phosphate trihydrate, and copper(I) iodide were purchased from Avantor Performance Materials Poland S.A (Gliwice, Poland) and used as received. 4-Aminophenol, palladium(II) acetate, bis(triphenylphosphine)palladium(II) chloride, and sodium hydride (60\% dispersion in mineral oil) were purchased from Sigma-Aldrich Sp. z.o.o (Poznan, Poland) and used as received. Pyridine was purchased from Lach-ner (Neratovice, Czech Republic) and used as received. Triethylamine was purchased from Chempur (Piekary Slaskie, Poland) and used 
as received. THF was distilled from sodium under nitrogen atmosphere prior to use. 2-(4(Trifluoromethoxy)phenyl)-1,3,2-dioxaborinane, 2-(3-fluoro-4 (trifluoromethoxy)phenyl)1,3,2-dioxaborinane, and 2-(3,5-difluoro-4-(trifluoromethoxy)phenyl)-1,3,2-dioxaborinane were synthesized in our laboratory; all the details of the synthesis and purification process are described in [58]. 1-Ethynyl-4-(trifluoromethoxy) benzene, 4-ethynyl-2-fluoro-1(trifluoromethoxy) benzene, and 5-ethynyl-1,3-difluoro-2-(trifluoromethoxy) benzene were synthesized in our laboratory; all the details of the synthesis and purification process are described in [57].

\subsection{Synthesis}

In this work, 13 previously unpublished rod-like compounds were synthesized and characterized. The compounds were divided into two main groups. The first group consisted of compounds based on the $4^{\prime}$-(trifluoromethoxy)-[1,1'-biphenyl]-4-yl-4-(trifluoromethoxy) benzoate core, and the second group consisted of compounds based on 4-((4(trifluoromethoxy) phenyl)ethynyl)phenyl-4-(trifluoromethoxy) benzoate (see Figure 1). Additionally compound 4-(trifluoromethoxy)phenyl-4-(trifluoromethoxy) benzoate was synthesized. Details of the synthetic procedures are given in the Supplementary Materials.
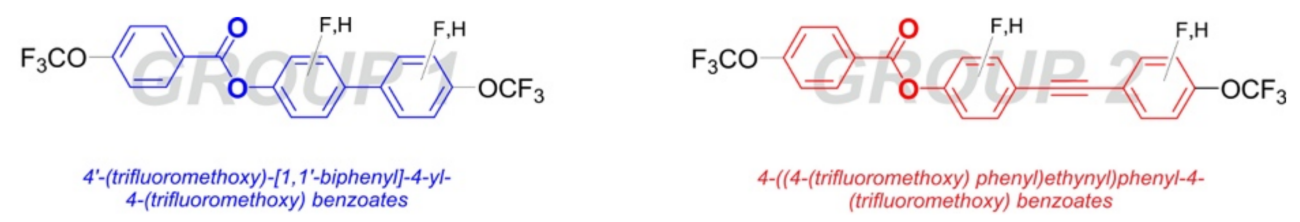

Figure 1. General structure of synthesized compounds.

The synthetic routes are shown in Figures 2-7. The differences between the compounds resulted from the different location of the lateral substituents for a given core.

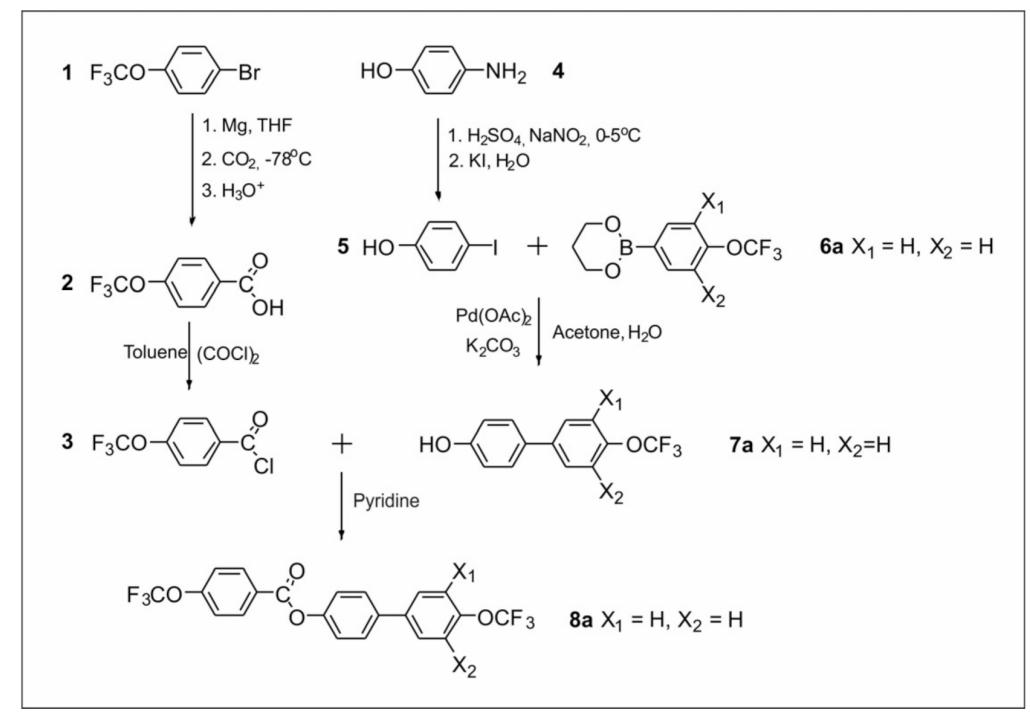

Figure 2. Synthesis of $4^{\prime}$-(trifluoromethoxy)-[1,1'-biphenyl]-4-yl 4-(trifluoromethoxy) benzoate 8a (variant A). 


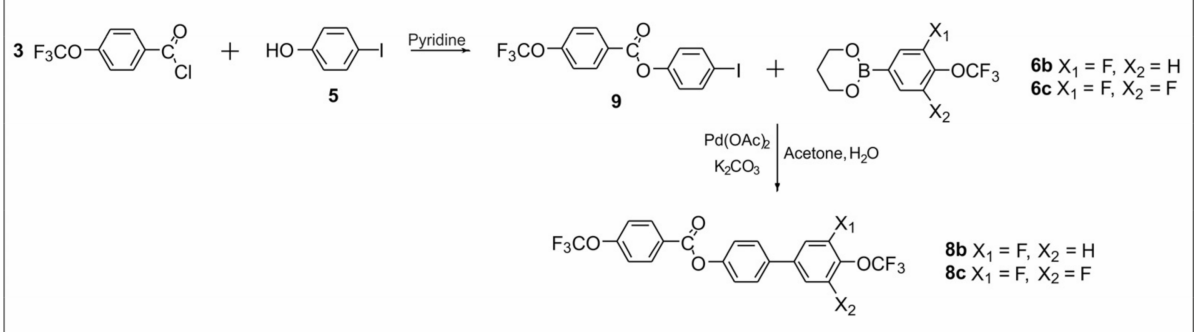

Figure 3. Synthesis of ester derivatives $\mathbf{8 b}$ and $\mathbf{8 c}$ (variant B).

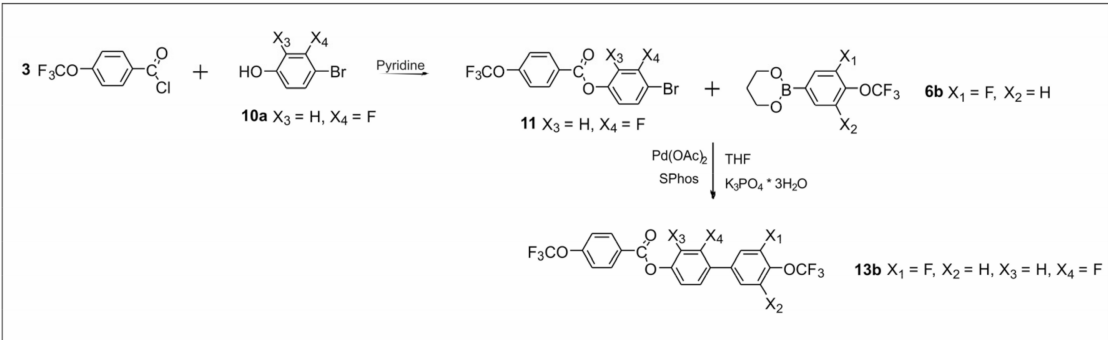

Figure 4. Synthesis of 2,3'-difluoro-4' -(trifluoromethoxy)-[1,1'-biphenyl]-4-yl 4-(trifluoromethoxy) benzoate $\mathbf{1 3 b}$.

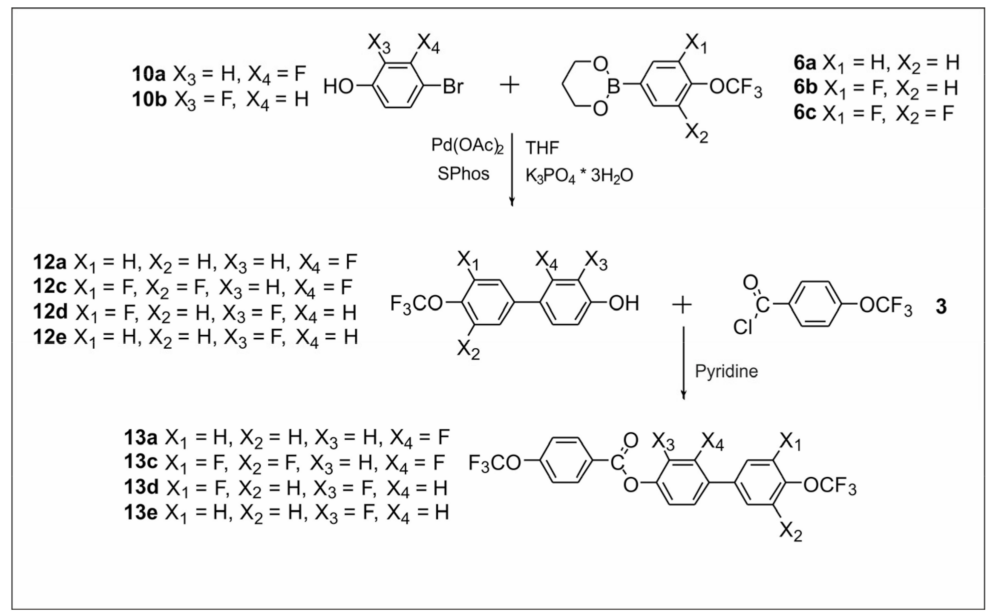

Figure 5. Synthesis of ester derivatives 13a, 13c, 13d, and 13e.

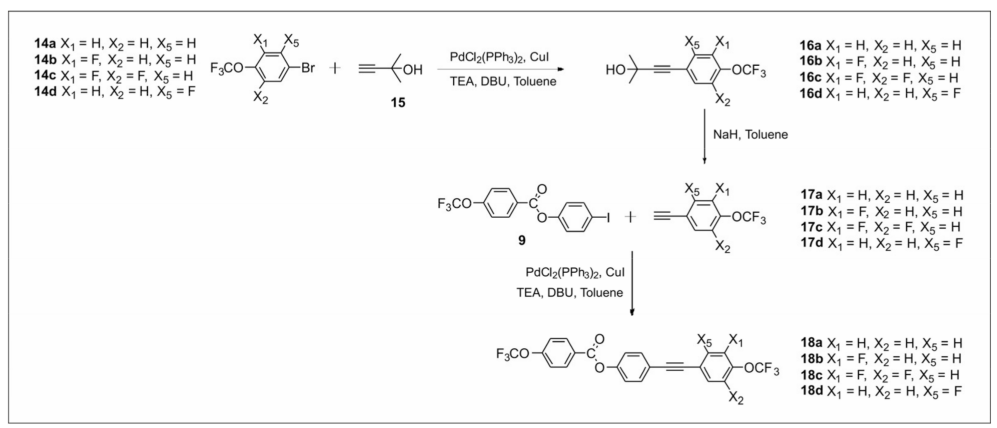

Figure 6. Synthesis of ester-tolane derivatives 18a-18d. 


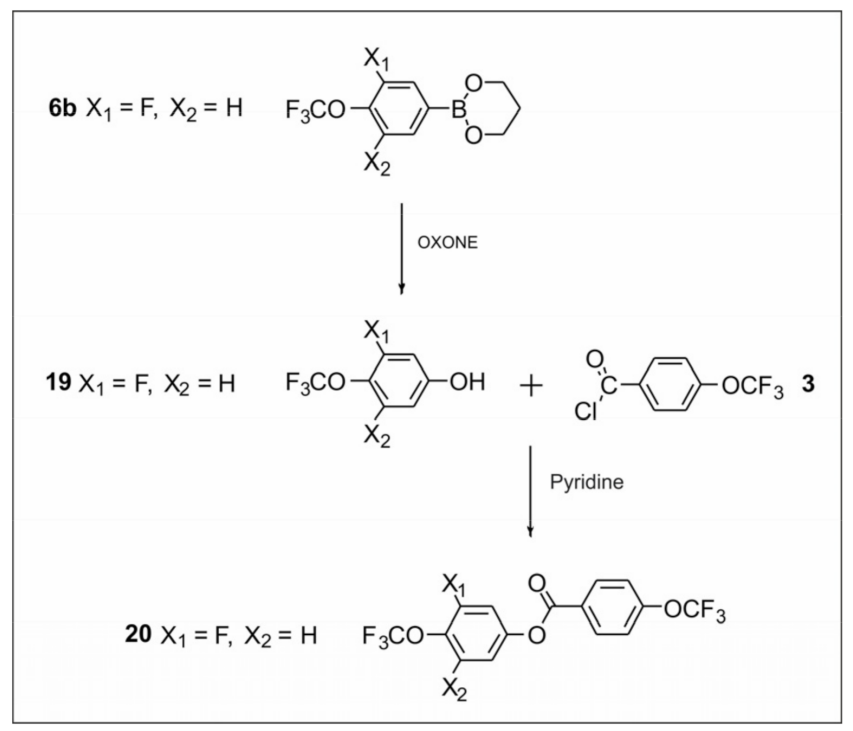

Figure 7. Synthesis of 3-fluoro-4-(trifluoromethoxy)phenyl 4-(trifluoromethoxy) benzoate 20.

Two different synthetic methodologies were chosen to synthesize the $4^{\prime}$-(trifluoromethoxy)[1,1'-biphenyl]-4-yl-4-(trifluoromethoxy) benzoate-based compounds. The first methodology (Figures 2 and 5) involved the synthesis of the appropriate derivative $4^{\prime}$-(trifluoromethoxy)-[1,1'biphenyl]-4-ol and 4-(trifluoromethoxy) benzoyl chloride. The last step was the esterification reaction, which led to the formation of the final product. This approach is used very often but requires the separate synthesis of the appropriate phenol each time lateral substitution is changed. The second methodology (Figures 3 and 4) involved preparing 4-halophenyl-4(trifluoromethoxy) benzoate and applying it in the Suzuki-Miyaura (SM) coupling reaction to obtain the final product. This approach seems more versatile as the resulting aryl halide can also be used in other coupling reactions. The second advantage is the high commercial availability of boronic acids. The main disadvantage of this approach is the possibility of an ester hydrolysis reaction in the SM coupling conditions.

For the synthesis of compounds based on the group 2 core 4-((4-(trifluoromethoxy) phenyl)ethynyl)phenyl-4-(trifluoromethoxy) benzoate (Figure 5) and the compound 4(trifluoromethoxy) phenyl 4-(trifluoromethoxy) benzoate (Figure 6), only one synthetic variant was carried out because these methodologies seem to be the most optimal and allow use of intermediates synthesized in the earlier stages.

\subsubsection{Synthesis of $4^{\prime}$-(Trifluoromethoxy)-[1,1'-biphenyl]-4-yl-4-(trifluoromethoxy) Benzoate Derivatives}

The synthesis of compound 8a (Figure 2, variant A) started with the preparation of 4(trifluoromethoxy) benzoic acid 2. For this, commercially available 1-bromo-4-(trifluoromethoxy) benzene was used, which was converted into Grignard reagent followed by the addition of solid $\mathrm{CO}_{2}$ at $-78{ }^{\circ} \mathrm{C}$. The obtained acid 2 was transformed into acid chloride 3 . The obtained product was poured into a volumetric flask, and the concentration was determined $\left(\mathrm{C}=0.87 \mathrm{~mol} / \mathrm{dm}^{3}\right)$. Product 3 was used for all syntheses in this work. The second key intermediate was biphenol derivative $7 \mathbf{a}$. Its synthesis began with the use of commercially available 4-aminophenol, which was converted into a diazonium salt and then into 4iodophenol 5 . The next step was the SM coupling of the previously synthesized boronic ester $\mathbf{6 a}$ and 4 -iodophenol $\mathbf{5}$. In this way, two key intermediates were synthesized, namely 3 and $7 \mathbf{a}$. The last step to obtain the final compound was the esterification reaction.

The synthesis of compounds $\mathbf{8 b}$ and $\mathbf{8 c}$ was performed using a different path (Figure 3, variant $B$ ). An esterification reaction was carried out using the previously synthesized intermediates 3 and 5. The 4-iodophenyl-4-(trifluoromethoxy) benzoate 9 obtained in this 
way was subjected to an SM coupling reaction with the previously prepared boroorganic esters $\mathbf{6 b}$ and $\mathbf{6 c}$. This course of action allowed two final compounds to be obtained.

Structures 13a-13d was initially planned to be synthesized using variant B. However, unexpected difficulties were encountered during the synthesis. Using the commercially available 4-bromo-3-fluorophenol 10a and the earlier obtained 4-(trifluoromethoxy) benzoyl chloride 3, intermediate $\mathbf{1 1}$ was synthesized in the first stage (Figure 4). However, the last step of the reaction turned out to be problematic. Under the SM coupling conditions, ester $\mathbf{1 1}$ was subjected to the hydrolysis process of ester linkage. Only compound $\mathbf{1 3} \mathbf{b}$ was obtained with this method. In the remaining cases, it was not possible to extract the final compounds, despite attempts to change the reaction conditions. Therefore, compounds 13a, 13c, and 13d were obtained using variant $A$. To obtain compounds 13a, 13c, and 13d (Figure 5), the corresponding $4^{\prime}$-(trifluoromethoxy)-[1, $1^{\prime}$-biphenyl]-4-ol derivatives had to be obtained. Therefore, for this purpose, the SM coupling reaction of bromophenols 10a and $10 \mathrm{~b}$ with previously synthesized organoboron esters $6 \mathbf{a}$ and $10 \mathrm{c}$ was performed. The last step to obtain the final compound was the esterification reaction.

\subsubsection{Synthesis of 4-((4-(Trifluoromethoxy)phenyl)ethynyl)phenyl-4-(trifluoromethoxy)} Benzoate Derivatives

The synthesis of compounds 18a-18d was performed as follows (Figure 6). In the first step of this synthesis, a monoprotected acetylene derivative was introduced into the aromatic ring. In the case of synthesized compounds, the source of the carbon-carbon triple bond was 2-methyl-3-butyn-2-ol 15, which is the cheapest commercially available monoprotected acetylene derivative. The second step was deprotection of the obtained derivative by the hydrolysis reaction using a catalytic amount of a base, in this case sodium hydride. The most commonly used solvent is toluene. Its boiling temperature is higher than the temperature of the removable protection (acetone), which is distilled off during the reaction, so sodium hydride can be added in catalytic amounts. This way, four key intermediates, namely $\mathbf{1 7 a}-\mathbf{1 7 d}$, were obtained. The last step to obtain the final compound was Sonogashira coupling.

\subsubsection{Synthesis of 4-(Trifluoromethoxy)phenyl-4-(trifluoromethoxy) Benzoate}

The last compound synthesized in this work was compound 20. It was prepared (Figure 7) by converting boronic ester $\mathbf{6} \mathbf{b}$ to phenol using oxidation reaction with commercially available oxone. Then, the final reaction was the ester linkage creation.

\subsection{Characterization and Measurements-Analytical Instrumentation}

Synthesis progress and purity of synthesized compounds were determined using Shimadzu GCMS-QP2010S series (Shimadzu, Kyoto, Japan) gas chromatograph equipped with a quadrupole mass analyzer (MS(EI)), high-performance liquid chromatography (HPLC-PDA-MS (APCI-ESI dual source)) using Shimadzu LCMS 2010 EV (Shimadzu, Kyoto, Japan) equipped with a polychromatic UV-vis detector (Shimadzu, Kyoto, Japan), and thin-layer chromatography (silica gel on aluminum). IR spectra (region 2-6 $\mu \mathrm{m}$ ) of the compounds as solutions in $\mathrm{CCl}_{4}\left(\mathrm{C}=0.05 \mathrm{mmol} / \mathrm{cm}^{3}\right)$ in square $10 \mathrm{~mm}$ cuvettes were collected at $25^{\circ} \mathrm{C}$ using Thermoscientific Nicolet iS10 (Thermo Fisher Scientific, Waltham, MA, USA). The phase transition temperatures and enthalpy data were determined by polarizing optical microscopy (POM) with an Olympus BX51 (Olympus, Shinjuku, Tokyo, Japan) equipped with a Linkam hot-stage THMS-600 (Linkam Scientific Instruments Ltd., Tadworth, UK) and differential scanning calorimeter SETARAM DSC 141 (KEP Technologies Group's DNA, Montauban, France) during heating/cooling cycles (with rate of $2^{\circ} / \mathrm{min}$ ). Refractive indices of neat materials and multicomponent nematic mixture were measured by the Metricon Model 2010/M Prism Coupler (Metricon Corporation, Pennington, NJ, USA) equipped with 443,636 , and $1550 \mathrm{~nm}$ lasers. Samples of liquid crystals were placed on glass plates rubbed with SE-130 polyimide (Nissan Chemical ${ }^{\circledR}$, Tokyo, Japan). Ordinary refractive index $n_{o}$ and extraordinary refractive index $n_{e}$ were measured separately using 
different polarization of incident beams. Samples were measured at elevated temperatures (5 Kelvin steps), with the limit of the setup being $200^{\circ} \mathrm{C}$.

\subsection{Mesomorphic Properties and Discussion}

Temperatures and enthalpies of phase transitions of synthesized compounds are listed in Table 1.

Table 1. Temperatures and enthalpies of phase transitions for synthesized compounds.

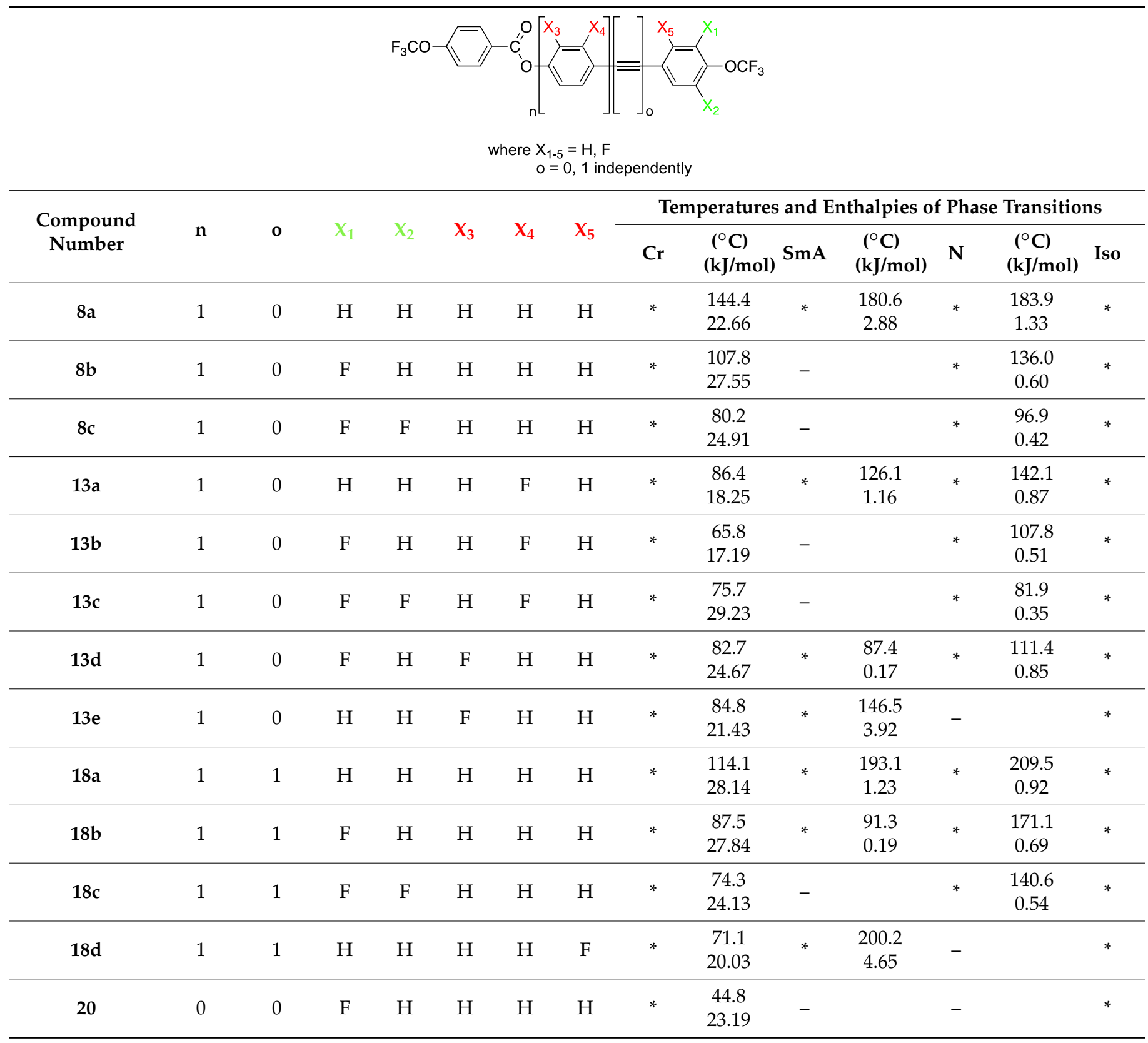

* means that a given phase is present; - means that a given phase does not exist.

Due to the location of the lateral substituents in the core, two position types were distinguished, namely inner core (red) and outer core (green) substituents. As mentioned earlier, two series of compounds were synthesized (see Figure 1), and these series had different features. The common feature for both series was the presence of the $\mathrm{CF}_{3} \mathrm{OPhCOO}$ group, in which no modifications were made. However, there were differences between these compounds that influenced the rest of the molecules. Group 1 included compounds 
in which the benzene rings were connected directly, and functionalization was performed only in the lateral position (acronyms 8a-13e). The second group included compounds in which a carbon-carbon triple bond was introduced between benzene rings, and functionalization was also performed only in the lateral position (acronyms 18a-18d). Moreover, an additional compound $\mathbf{2 0}$ was synthesized, which allowed us to find the correlation between the structure of the compound and its mesomorphic properties. This was one of the components of the multicomponent mixture, which helped to lower the clearing temperature and enhanced the miscibility between materials.

To better illustrate the correlations, the results are presented in the Figures 8-12. Figure 8 shows the influence of the number and position of fluorine atoms in the lateral position on the mesomorphic properties for selected derivatives of group 1.

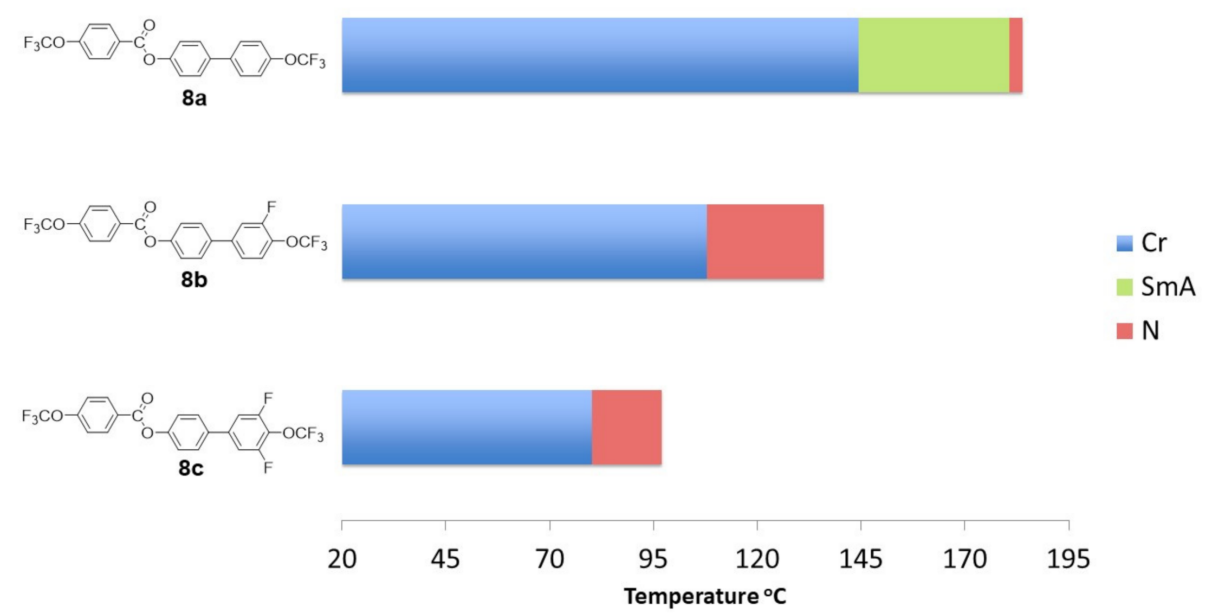

Figure 8. The influence of the number and position of fluorine atoms in the lateral position on the mesomorphic properties for selected group 1 derivatives (direct connection between benzene units).

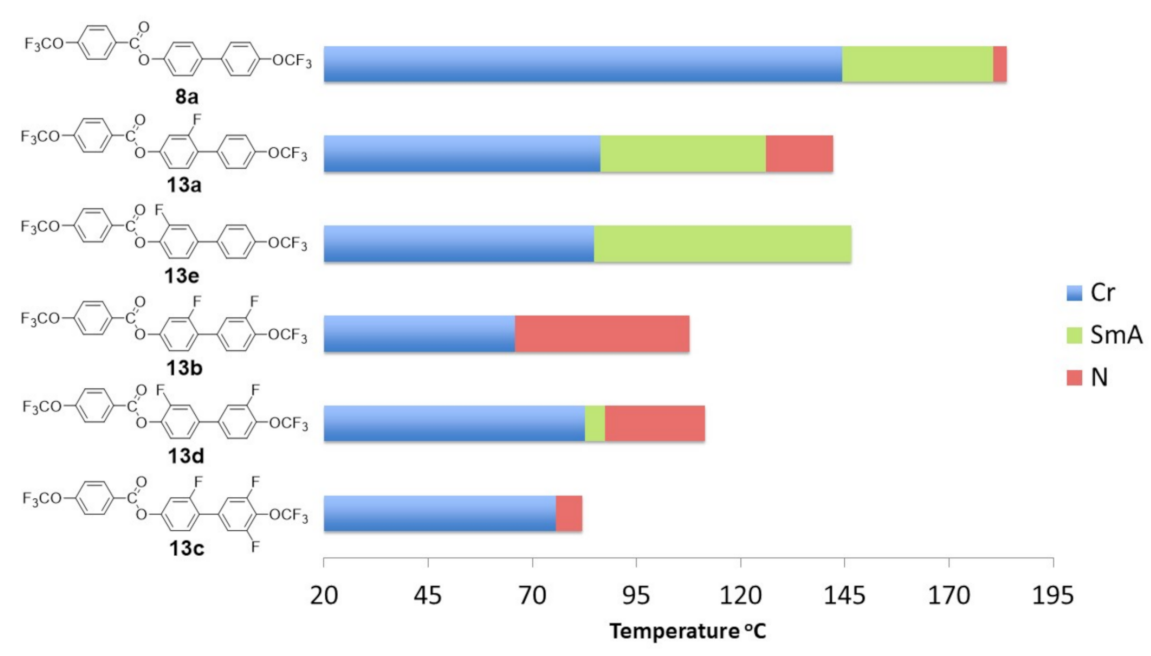

Figure 9. The influence of the number and position of fluorine atoms in the lateral position on the mesomorphic properties for selected group 1 derivatives (direct connection between benzene units). 


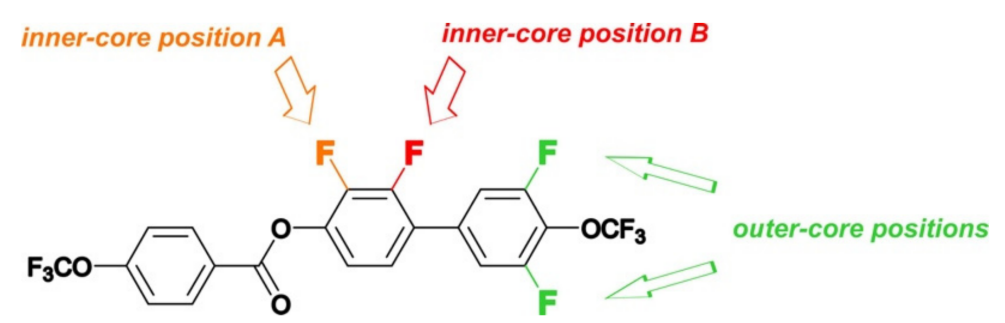

Figure 10. Positions of fluorine substituents in $4^{\prime}$-(trifluoromethoxy)-[1,1'-biphenyl]-4-yl-4(trifluoromethoxy) benzoates (group 1 compounds): inner core position A (orange), inner core position B (red), and outer core position (green).

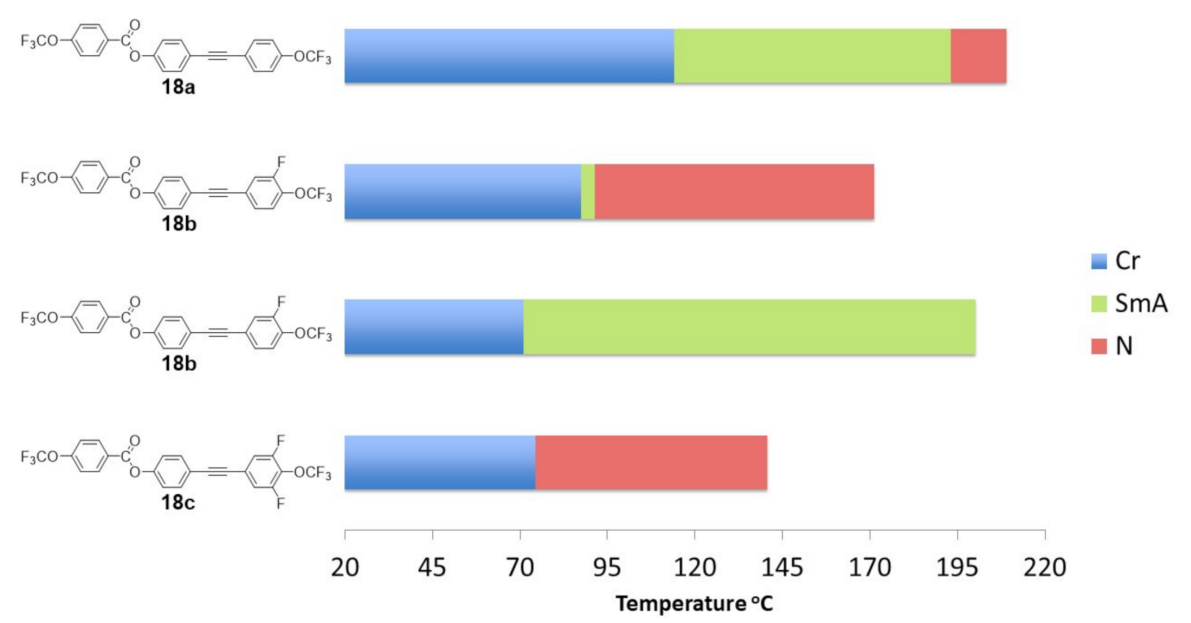

Figure 11. The influence of the number and position of fluorine atoms in the lateral position on the mesomorphic properties of tolane derivatives.
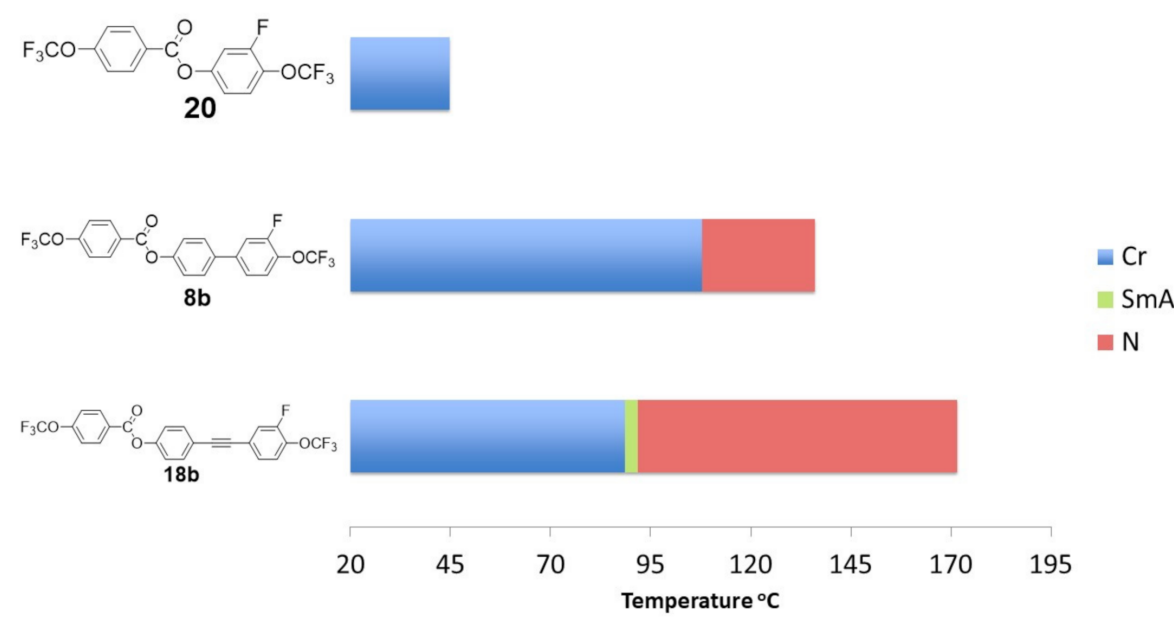

Figure 12. The influence of the core structure on the mesomorphic properties.

The unsubstituted compound 8a showed a high melting temperature (above $140{ }^{\circ} \mathrm{C}$ ). A smectic A phase occurred, and a very narrow $\left(3.3^{\circ} \mathrm{C}\right)$ nematic phase range was observed. Compound 8a could be treated as a core and primary structure of group 1 compounds $\mathbf{8 b}-\mathbf{1 3 e}$, which differed in the number and location of fluorine atoms in the lateral position. The introduction of the fluorine atom $\mathbf{8 b}$ in the outer core position caused a decrease in the melting temperature by $36.6^{\circ} \mathrm{C}$. Moreover, destabilization of the highly ordered smectic phase A was noticed, which resulted in the temperature range of the nematic phase increasing significantly by $24.9^{\circ} \mathrm{C}$. The subsequent introduction of a fluorine atom in the outer core position $\mathbf{8 c}$ further lowered the melting point and narrowed the temperature range of the nematic phase. 
Figure 9 shows the next observed correlations resulting from the number and location of fluorine atoms in the core.

For a detailed analysis of the properties, the internal separation of substituents were introduced at the inner core positions into A and B, marked in orange and red, respectively, in Figure 10. Compounds $\mathbf{1 3} \mathbf{a}-\mathbf{c}$, in which the fluorine atom was directed toward the adjacent benzene ring, were collected in set B. Set A included compounds $\mathbf{1 3 e}$ and $\mathbf{1 3 d}$, which had a lateral substituent directed toward the ester group. The introduction of one fluorine atom 13a into the rigid core showed the stabilizing effect of the smectic phase (its temperature range did not change). However, the melting temperature dropped significantly by $58.0^{\circ} \mathrm{C}$ and widened the range of the nematic phase by $12.7^{\circ} \mathrm{C}$. In the case of compound 13e, where there was also only one fluorine atom (inner core position A), a significant extension of the temperature range of the smectic phase by $22.0^{\circ} \mathrm{C}$ and destabilization of the nematic phase were observed. Moreover, the melting point practically did not change (compared to 13a). Further introduction of the fluorine atom in the outer core position (13b and $\mathbf{1 3 d}$ ) caused a drastic change in the mesophase morphology. In the case of compound $\mathbf{1 3 b}$, the smectic phase disappeared completely, the range of the nematic phase was significantly widened by $26.0^{\circ} \mathrm{C}$, and the melting point was lowered. However, for compound 13e, the observations were slightly different. First of all, no drop in the melting point was observed, the range of the smectic phase was significantly narrowed by $57.0^{\circ} \mathrm{C}$, and the nematic phase also appeared. Subsequent introductions of a fluorine atom in the outer core position (13c) increased the melting point and narrowed the range of the nematic phase. It is worth noting that the compounds from set A had a much stronger tendency to create smectic phases. One general conclusion that can be drawn from the figures above is that if the lateral substituent (fluorine atom) was in the inner core position (both A or B), the compounds tended to form smectic phases. The reverse was true if the substituent was in the outer core position, with increased nematogeneity being observed. A similar relationship was found for compounds from group 2, which had carbon-carbon triple bond introduced between benzene rings (acronyms 18a-18d) (see Figure 11). Taking into account the stability of the nematic phase, the optimal number of fluorine atoms in a rigid core should not be greater than 2 .

Figure 11 shows the influence of the number and position of fluorine atoms in the lateral position on the mesomorphic properties of tolane derivatives.

The unsubstituted compound 18a showed a melting point above $110^{\circ} \mathrm{C}$, a temperaturewide smectic phase $\mathrm{A}\left(79.0^{\circ} \mathrm{C}\right.$ range), and a temperature-narrow nematic phase. Compound 18a could be somehow treated as a source of compounds $\mathbf{1 8 b}-\mathbf{1 8 d}$, which differed in the number and location of fluorine atoms in the lateral position. The introduction of one fluorine atom into the core had a dramatic effect on the phase appearance. The fluorine atom in the outer core position (18b) strongly destabilized the presence of the smectic phase. Moreover, the temperature range of the nematic phase was significantly extended by $63.8{ }^{\circ} \mathrm{C}$, and the melting point was lowered. On the other hand, when the fluorine atom was in the inner core position (18d), the compound exhibited only a smectic phase in a very wide range $\left(129.1^{\circ} \mathrm{C}\right)$ and even lower melting point. Further introduction of the fluorine atom in the outer core position (18c) caused the complete disappearance of the smectic phase, lowering the melting point and narrowing the range of the nematic phase by $13.5^{\circ} \mathrm{C}$.

Figure 12 shows the influence of the core structure on the mesomorphic properties.

As described in previous works [57-59] in the case of mesomorphs dedicated to infrared applications, where short perfluorinated chains are used, the presence of liquid crystalline phases is mainly related to the structure of the core itself. Functionalization in the lateral position helps to fine-tune expected parameters such as mesophase morphology, temperature range, and clearing and melting temperatures. Figure 12 confirms this observation. With the elongation of the rigid core, the temperature range of the liquid crystalline phase increased. Moreover, the above described correlations clearly show the crucial role of 
the number and position of the lateral substituents on the type of liquid crystalline phases that occur.

\subsection{IR (2-6 $\mu \mathrm{m})$ Absorption Properties}

One of the goals of this research was the synthesis of new compounds that show reduced absorption in the infrared range, especially in the range of 2-6 $\mu \mathrm{m}$ (MWIR). Due to the fact that the obtained spectra were virtually identical for each of the compounds investigated here, separate IR spectra for each compound are not shown. Figure 13 shows the transmittance spectra for selected compounds from groups 1 and 2 (blue and green lines). Two previously reported compounds have also been added to the graphics to show the influence of the core structure on properties in the range of 2-6 $\mu \mathrm{m}$ (black and red lines). Moreover, the properties of the compounds investigated here were correlated with the most commonly used nematic 5CB (4-cyano-4'-pentylbiphenyl; show as orange line in the figure). The choice of $5 \mathrm{CB}$ was not accidental. It was chosen because its structure, i.e., a rigid core and the presence of an elastic aliphatic chain and a group generating a strong dipole moment, is common to the vast majority of liquid crystals that have been synthesized and used so far. This allowed visualization of the differences between the "older generation" materials and those dedicated to infrared. First, the absorption bands associated with infrared-transparent compounds were analyzed.

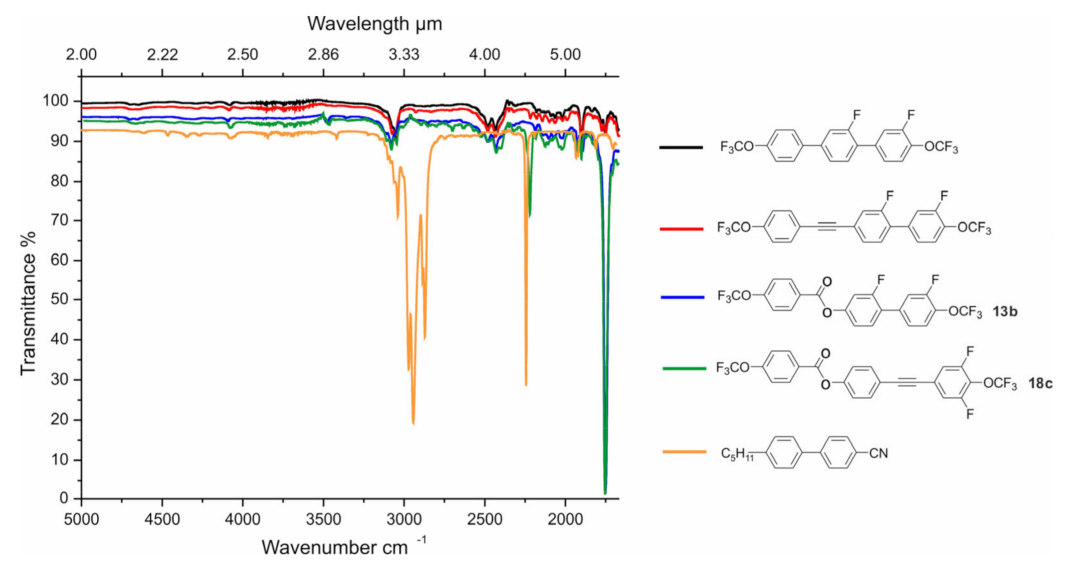

Figure 13. Spectral properties in the range of 2-6 $\mu \mathrm{m}$ for selected compounds: terphenyl (in black) [57], phenyltolane (in red) [58], 13b (in blue), 18c (in green), and 5CB (in orange).

The absorption bands, shown in Figure 13, were closely related to their structure. In the case of compounds dedicated to infrared, the strongest absorption band at $\lambda \sim$ $5.7 \mu \mathrm{m}\left(1754 \mathrm{~cm}^{-1}\right)$ came from the basic vibrations of the $\mathrm{C}=\mathrm{O}$ bond from the carbonyl group. Another narrow, moderately intense absorption band at $\lambda \sim 4.5 \mu \mathrm{m}\left(2128 \mathrm{~cm}^{-1}\right)$ was associated with the presence of the $\mathrm{C} \equiv \mathrm{C}$ bond. However, the intensity of these vibrations changed with the anharmonicity change of the oscillator, which was the R1$\mathrm{C} \equiv \mathrm{C}-\mathrm{R} 2$ system, as detailed in [57]. The different intensities of this band for different structures containing the $\mathrm{C} \equiv \mathrm{C}$ triple bond were also directly related to the presence of fluorine atoms in positions proximal to the $\mathrm{OCF}_{3}$ group [62]. There were also quite wide, low intensity peaks at around $\lambda \sim 4.2 \mu \mathrm{m}\left(2381 \mathrm{~cm}^{-1}\right)$, which originated from the overtone $\mathrm{C}-\mathrm{F}$ and $\mathrm{C}-\mathrm{O}$ bonds. Basic vibrations for $\mathrm{C}-\mathrm{F}$ bond $\left(\mathrm{CF}, \mathrm{CF}_{2}\right.$, and $\left.\mathrm{CF}_{3}\right)$ were in the range of 7.1-9.5 $\mu \mathrm{m}\left(1408-1052 \mathrm{~cm}^{-1}\right)$, while basic vibrations for single $\mathrm{C}-\mathrm{O}$ bond were in the range of $7.68-8.65 \mu \mathrm{m}\left(1302-1156 \mathrm{~cm}^{-1}\right)$. It had a small absorption peak at around $\lambda \sim 3.3 \mu \mathrm{m}$ $\left(3030 \mathrm{~cm}^{-1}\right)$ derived from the $\mathrm{C}-\mathrm{H}$ bond vibrations in the aromatic rings. The last peak of very low intensity, which was placed at $\lambda \sim 2.9 \mu \mathrm{m}\left(3448 \mathrm{~cm}^{-1}\right)$, originated from the overtone $\mathrm{C}=\mathrm{O}$.

Comparing the spectra of compounds dedicated to infrared and $5 \mathrm{CB}$, it was found that the very wide and strong intensity peak at $\lambda \sim 3.0-3.5\left(3333-2857 \mathrm{~cm}^{-1}\right)$ came mainly from the vibrations of $\mathrm{C}-\mathrm{H}$ bonds in the aliphatic chain. The second peak, which was 
narrow and also of strong intensity, was related to the CN group. This indicated that the change in molecular design resulted in a new generation of infrared-dedicated materials. Moreover, the obtained ester derivatives, due to their structure, had additional absorption bands. However, they could still be treated as materials showing high transparency in the infrared range.

\subsection{Optical Properties}

Six investigated structures were selected for measurement of optical properties. The exact values of refractive indices $n_{o}$ and $n_{e}$ are given in the Supplementary Materials. Figure 14 shows a graphical comparison of the measured values for six selected structures, namely $8 b, 8 c, 13 b, 13 c, 18 b$, and 18c.

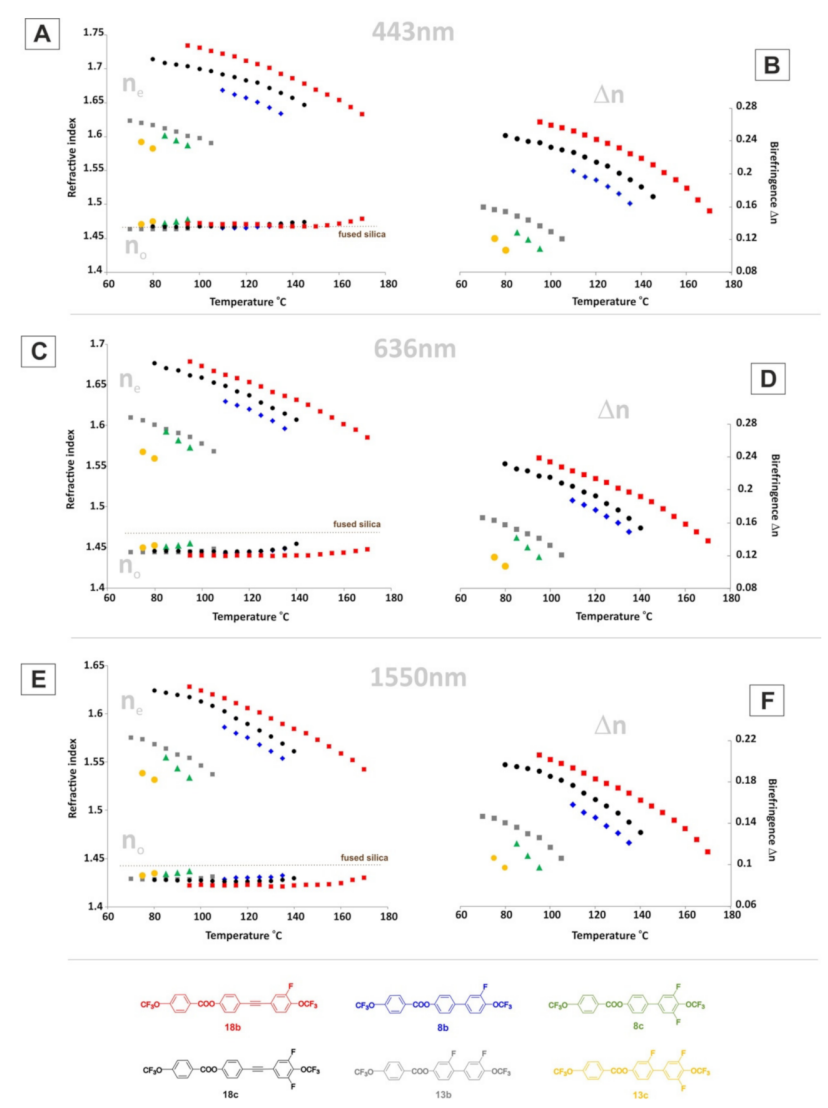

Figure 14. Temperature dependence of refractive indices $n_{0}$ and $n_{e}(A, C, E)$ and birefringence $\Delta n$ (B,D,F) measured for $\mathbf{8 b}, \mathbf{8 c}, \mathbf{1 3 b}, \mathbf{1 3 c}, \mathbf{1 8 b}$, and $\mathbf{1 8 c}$ at $\lambda=443,636$, and $1550 \mathrm{~nm}$.

With the optical data obtained for $636 \mathrm{~nm}$ for five tested compounds, namely $\mathbf{8 b}, \mathbf{8 c}$, $\mathbf{1 3 b}, \mathbf{1 8 b}$, and 18c (the nematic shown by compound 13c was too narrow), we estimated the macroscopic order parameter $S$ using the Haller extrapolation, which proposed the following relation [69]:

$$
\mathrm{S}=\left(1-\frac{\mathrm{T}}{\mathrm{T}_{\mathrm{NI}}}\right)^{\beta}
$$

where $T / T_{N I}$ is reduced temperature, and $\beta$ is an adjustable parameter. Anisotropic properties such as birefringence $\Delta \mathrm{n}$ and its temperature dependence in the nematic phase is given by the following relation: [70]

$$
\Delta \mathrm{n}=\Delta \mathrm{n}_{0}\left(1-\frac{\mathrm{T}}{\mathrm{T}_{\mathrm{NI}}}\right)^{\beta}
$$


where $\Delta \mathrm{n}_{\mathrm{o}}$ is the value of the birefringence in perfect order at $0 \mathrm{~K}$. The parameters $\Delta \mathrm{n}_{\mathrm{o}}$ and $\beta$ were obtained by fitting the experimental data for $\Delta \mathrm{n}$ to the following equation written in logarithmic form (3):

$$
\log \Delta \mathrm{n}=\log \Delta \mathrm{n}_{0}+\beta \log \left(\frac{\mathrm{T}_{\mathrm{NI}}-\mathrm{T}}{\mathrm{T}_{\mathrm{NI}}}\right)
$$

Then, the required order parameter $\mathrm{S}$ was obtained by substituting this value in (1). Variation of $S$ values with reduced temperature $\left(T / T_{N I}\right)$ for five investigated structures is given in Figure 15.

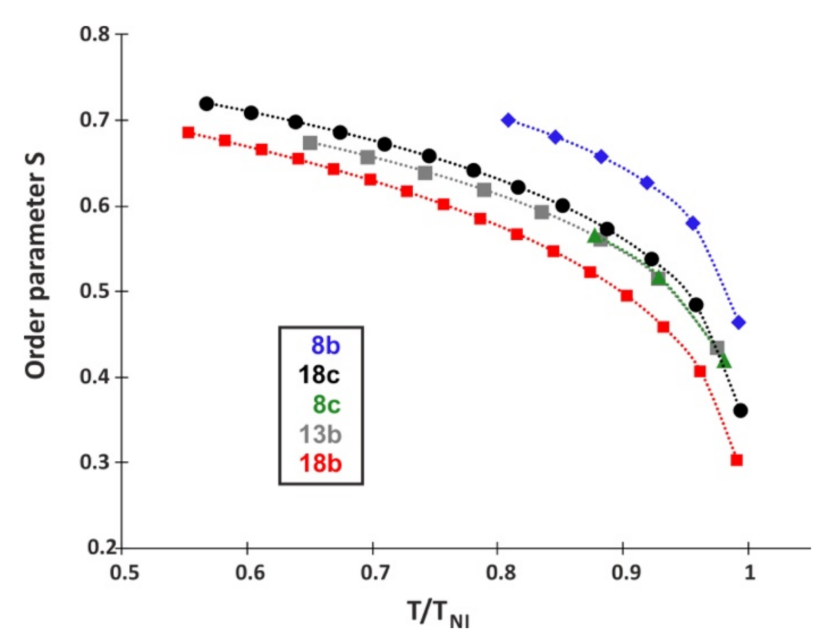

Figure 15. Temperature dependence of order parameter $S$ for $\mathbf{8 b}, \mathbf{8 c}, \mathbf{1 3 b}, \mathbf{1 8 b}$, and $\mathbf{1 8 c}$.

Comparing the biphenyl benzoate structures (group 1), it was found that each successive fluorine atom in the rigid core of the molecule caused a decrease in the value of birefringence $\Delta \mathrm{n}$ for each wavelength. The same behavior was noticed among structures with triple $\mathrm{C} \equiv \mathrm{C}$ bond (group 2). The presence of a triple bond in the core of the molecule caused an increase in the value of extraordinary refractive index, and thus birefringence, compared to the biphenyl benzoate structures. The values of order parameter for all samples were found to gradually decrease with increase in temperature. The tested compounds were characterized with standard values of parameter $\mathrm{S}(0.3<\mathrm{S}<0.7)$ in nematic phases; however, compound $\mathbf{8 b}$ differed from the others, with slightly higher values of $S$.

The additional advantage of the liquid crystals tested here is the very low values of ordinary refractive indices, which are lower than those found for fused silica [71-74].

However, measurements were made at elevated temperatures, well above room temperature. Encouraged by this fact, we composed a nematic multicomponent mixture from the examined structures that covered temperatures even below room temperature. The weight composition of the nematic multicomponent mixture at room temperature $\left(\mathrm{T}_{\mathrm{Cr}-\mathrm{N}}<0{ }^{\circ} \mathrm{C}, \mathrm{T}_{\mathrm{N}-\mathrm{Iso}}=52.0-54.9^{\circ} \mathrm{C}\right)$ is given in the Supplementary Materials.

For the test mixture, measurements of the refractive indices were also made for three wavelengths $(443,636$, and $1550 \mathrm{~nm})$ in a wide temperature range. The refractive index data for the multicomponent mixture are given in the Supplementary Materials.

With the values of the refractive indices $n_{e}$ and $n_{o}$ for any three wavelengths, we used the methods of mathematical model fitting to the experimental results to determine the exact values of the three coefficients of the Cauchy equation (Equation (4)) $\mathrm{A}_{\mathrm{e}, \mathrm{o}}, \mathrm{B}_{\mathrm{e}, \mathrm{o}}$, and $\mathrm{C}_{\mathrm{e}, \mathrm{o}}$ given in Table 2:

$$
\mathrm{n}_{\mathrm{e}, \mathrm{o}}=\mathrm{A}_{\mathrm{e}, \mathrm{o}}+\frac{\mathrm{B}_{\mathrm{e}, \mathrm{o}}}{\lambda^{2}}+\frac{\mathrm{C}_{\mathrm{e}, \mathrm{o}}}{\lambda^{4}}
$$


Table 2. Fitting parameters for the extended Cauchy model at $20^{\circ} \mathrm{C}$ using the experimental data measured at 443,636 , and $1550 \mathrm{~nm}$ wavelengths for multicomponent nematic mixture.

\begin{tabular}{ccccccc}
\hline \multirow{2}{*}{ Temperature $\left[{ }^{\circ} \mathbf{C}\right]$} & \multicolumn{3}{c}{$\mathbf{n}_{\mathbf{o}}$} & \multicolumn{2}{c}{$\mathbf{n}_{\mathbf{e}}$} \\
\cline { 2 - 6 } & $\mathbf{A}_{\mathbf{o}}$ & $\mathbf{B}_{\mathbf{o}}$ & $\mathbf{C}_{\mathbf{o}}$ & $\mathbf{A}_{\mathbf{e}}$ & $\mathbf{B}_{\mathbf{e}}$ & $\mathbf{C}_{\mathbf{e}}$ \\
\hline 20 & 1.4323 & $1.0331 \times 10^{4}$ & $-2.7761 \times 10^{8}$ & 1.5654 & $1.3305 \times 10^{4}$ & $6.4903 \times 10^{8}$ \\
\hline
\end{tabular}

With Cauchy coefficients, we further calculated the refractive index and birefringence dispersion in a large range of electromagnetic spectrum (see Figure 16). At room temperature $\left(20^{\circ} \mathrm{C}\right)$, the material was again found to have low ordinary refractive indices, with values below those reported for fused silica for some spectral range.

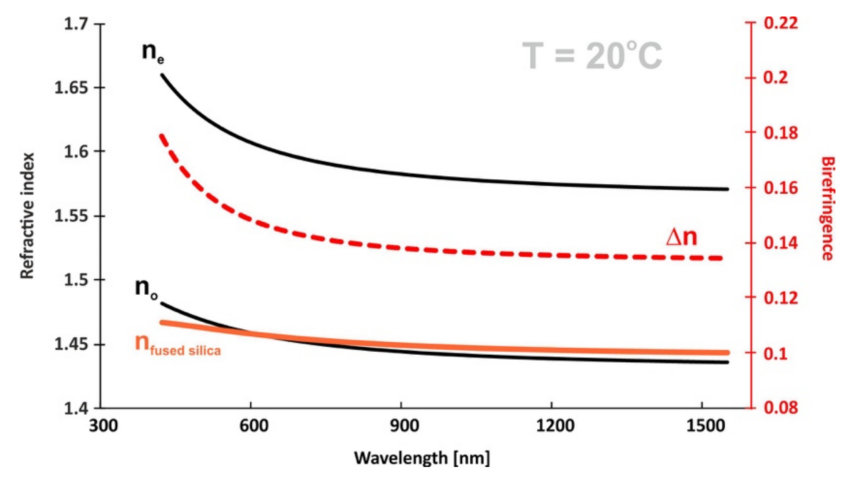

Figure 16. Dispersion of refractive indices (black) and birefringence (red) for multicomponent nematic mixture and refractive index of fused silica (brown) at $20^{\circ} \mathrm{C}$.

Such materials are desirable for use as an overlayer or cladding layer on fused silica waveguides [64-66]. So far, most of the known liquid crystal materials showing a similar effect were built from hydrocarbons without $\pi$-delocalized bonded groups $[67,68]$. Accordingly, the birefringence values of such LCs were very low $(\Delta \mathrm{n} \approx 0.05)$. In this work, the liquid crystal structures showed a completely different molecular approach. Cores of the molecules were made of only aromatic rings as well as triple $\mathrm{C} \equiv \mathrm{C}$ bonds rich in $\pi$-electrons. This in turn translated into much higher values of birefringence.

\section{Conclusions}

As part of this study, 13 previously unpublished compounds were obtained, which were characterized by reduced infrared absorption, in particular in the range of 2-5.7 $\mu \mathrm{m}$. Based on the physicochemical research performed, the following conclusions can be drawn:

- Of the synthesized compounds, 12/13 had enantiotropic liquid crystalline phases.

- Compounds with inner core lateral substitution tended to form temperature-stable smectic phases. The situation was different in the case of outer core, where nematic phases were observed.

- From the viewpoint of the nematic phase, the optimal number of fluorine atoms in a rigid core should not be greater than 2 .

- The presence of absorption bands in the range of 2-6 $\mu \mathrm{m}$ is inevitable if a compound is to exhibit mesomorphic properties. Most often, these bands come from the vibrations of the $\mathrm{C}-\mathrm{H}$ bonds from the rigid core or the $\mathrm{C}-\mathrm{O}$ and $\mathrm{C}-\mathrm{F}$ bonds related to the functionalization in the terminal and lateral positions. 
Supplementary Materials: The following are available online at https: / www.mdpi.com/article/ 10.3390/ma14102616/s1, Figure S1: DSC spectrum for compound of 8a, Figure S2: DSC spectrum for compound of $\mathbf{8 b}$, Figure S3: DSC spectrum for compound of $8 c$, Figure S4: DSC spectrum for compound of 13a, Figure S5: DSC spectrum for compound of 13b, Figure S6: DSC spectrum for compound of 13c, Figure S7: DSC spectrum for compound of 13d, Figure S8: DSC spectrum for compound of 13e, Figure S9: DSC spectrum for compound of 18a, Figure S10: DSC spectrum for compound of 18b, Figure S11: DSC spectrum for compound of 18c, Figure S12: DSC spectrum for compound of 18d, Figure S13: DSC spectrum for compound of 20, Figure S14: MS spectrum for compound of 2, Figure S15: MS spectrum for compound of 5, Figure S16: MS spectrum for compound of 7a, Figure S17: MS spectrum for compound of $\mathbf{8 a}$, Figure S18: MS spectrum for compound of $\mathbf{8 b}$, Figure S19: MS spectrum for compound of $\mathbf{8 c}$, Figure S20: MS spectrum for compound of $\mathbf{9}$, Figure S21: MS spectrum for compound of 11, Figure S22: MS spectrum for compound of 12a, Figure S23: MS spectrum for compound of 12c, Figure S24: MS spectrum for compound of 12d, Figure S25: MS spectrum for compound of 12e, Figure S26: MS spectrum for compound of 13a, Figure S27: MS spectrum for compound of 13b, Figure S28: MS spectrum for compound of 13c, Figure S29: MS spectrum for compound of 13d, Figure S30: MS spectrum for compound of 13e, Figure S31: MS spectrum for compound of $\mathbf{1 6 d}$, Figure S32: MS spectrum for compound of 17d, Figure S33: MS spectrum for compound of 18a, Figure S34: MS spectrum for compound of 18b, Figure S35: MS spectrum for compound of 18c, Figure S36: MS spectrum for compound of 18d, Figure S37: MS spectrum for compound of 19, Figure S38: MS spectrum for compound of 20, Table S1: Measured refractive indices $\left(n_{e}\right.$ and $\left.n_{0}\right)$ of $8 b$ at $\lambda=443,636$, and $1550 \mathrm{~nm}$, and at different temperatures, Table S2: Measured refractive indices $\left(\mathrm{n}_{\mathrm{e}}\right.$ and $\left.\mathrm{n}_{\mathrm{o}}\right)$ of $\mathbf{1 3 b}$ at $\lambda=443,636$, and $1550 \mathrm{~nm}$, and at different temperatures, Table S3: Measured refractive indices $\left(n_{e}\right.$ and $\left.n_{0}\right)$ of $8 c$ at $\lambda=443,636$, and $1550 \mathrm{~nm}$, and at different temperatures, Table S4: Measured refractive indices $\left(n_{e}\right.$ and $\left.n_{o}\right)$ of $13 c$ at $\lambda=443$, 636, and $1550 \mathrm{~nm}$, and at different temperatures, Table S5: Measured refractive indices $\left(\mathrm{n}_{\mathrm{e}}\right.$ and $\left.\mathrm{n}_{\mathrm{o}}\right)$ of $\mathbf{1 8 b}$ at $\lambda=443,636$, and $1550 \mathrm{~nm}$, and at different temperatures, Table S6: Measured refractive indices $\left(n_{e}\right.$ and $\left.n_{0}\right)$ of $13 c$ at $\lambda=443,636$, and $1550 \mathrm{~nm}$, and at different temperatures, Table S7: Weight composition and phase transition temperatures of nematic mixture, Table S8: Measured refractive indices $\left(n_{e}\right.$ and $\left.n_{o}\right)$ of multicomponent nematic mixture at $\lambda=443,636$, and $1550 \mathrm{~nm}$, and at different temperatures.

Author Contributions: Conceptualization, synthesis, methodology, writing and editing, P.H.; synthesis, measurements, writing, editing, and formulation of the mixture, J.H. All authors have read and agreed to the published version of the manuscript.

Funding: This work was financially supported by the National Science Centre Poland, grant UMO2012/05/D/ST5/03387, and Military University of Technology project UGB 22-840/2021.

Institutional Review Board Statement: Not applicable.

Informed Consent Statement: Not applicable.

Data Availability Statement: Data is contained within the article or supplementary material.

Acknowledgments: The authors would like to thank Justyna Dziewiątkowska and Patryk Kobyliński for help in the synthesis of compounds.

Conflicts of Interest: The authors declare no conflict of interest.

\section{References}

1. Li, X.; Tan, N.; Pivnenko, M.; Sibik, J.; Zeitler, J.A.; Chu, D. High-birefringence nematic liquid crystal for broadband THz applications. Liq. Cryst. 2016, 43, 955-962. [CrossRef]

2. Pauluth, D.; Tarumi, K. Advanced liquid crystals for television. J. Mater. Chem. 2004, 14, 1219-1227. [CrossRef]

3. Pauluth, D.; Tarumi, K. Optimization of liquid crystals for television. J. Soc. Inf. Disp. 2005, 13, 693-702. [CrossRef]

4. Chigrinov, V.G.; Yakovlev, D.A. Optimization and modeling of liquid crystal displays. Mol. Cryst. Liq. Cryst. 2006, 453, 107-121. [CrossRef]

5. Cheng, Z.; Wang, T.; Li, X.; Zhang, Y.; Yu, H. NIR-Vis-UV light-responsive actuator films of polymer-dispersed liquid crystal/graphene oxide nanocomposites. ACS Appl. Mater. Interfaces 2015, 7, 27494-27501. [CrossRef]

6. Yaghmaee, P.; Karabey, O.H.; Bates, B.; Fumeaux, C.; Jakoby, R. Electrically tuned microwave devices using liquid crystal technology. Int. J. Antennas Propag. 2013, 2013, 824214. [CrossRef] 
7. Mittra, R.; Nasri, A.; Donia, O.; Rmili, H. Novel Low-cost Phase Shifters for Millimeter Wave Applications; IEEE: Piscataway, NJ, USA, 2018; pp. 2127-2128.

8. Nose, T.; Ito, R.; Honma, M. Potential of liquid-crystal materials for millimeter-wave application. Appl. Sci. Basel 2018, 8, 2544. [CrossRef]

9. Polat, E.; Tesmer, H.; Reese, R.; Nickel, M.; Wang, D.; Schumacher, P.; Jakoby, R.; Maune, H. Reconfigurable millimeter-wave components based on liquid crystal technology for smart applications. Crystals 2020, 10, 346. [CrossRef]

10. Kowerdziej, R.; Parka, J.; Krupka, J.; Olifierczuk, M.; Nowinowski-Kruszelnicki, E.; Jaroszewicz, L.; Chojnowska, O. Dielectric properties of highly anisotropic nematic liquid crystals for tunable microwave components. Appl. Phys. Lett. 2013, 103, 172902. [CrossRef]

11. Reuter, M.; Garbat, K.; Vieweg, N.; Fischer, B.M.; Dabrowski, R.; Koch, M.; Dziaduszek, J.; Urban, S. Terahertz and optical properties of nematic mixtures composed of liquid crystal isothiocyanates, fluorides and cyanides. J. Mater. Chem. C 2013, 1, 4457-4463. [CrossRef]

12. Reuter, M.; Vieweg, N.; Fischer, B.M.; Mikulicz, M.; Koch, M.; Garbat, K.; Dabrowski, R. Highly birefringent, low-loss liquid crystals for terahertz applications. APL Mater. 2013, 1, 012107. [CrossRef]

13. Chodorow, U.; Parka, J.; Kula, P.; Herman, J.; Chojnowska, O.; Dabrowski, R.; Chigrinov, V.G. Terahertz properties of fluorinated liquid crystals. Liq. Cryst. 2013, 40, 1586-1590. [CrossRef]

14. Chodorow, U.; Chojnowska, O.; Garbat, K.; Herman, J.; Parka, J. Liquid crystal materials with high birefringence for THz applications. In Proceedings of the 2014 39th International Conference on Infrared, Millimeter, and Terahertz Waves (Irmmw-Thz), Tucson, AZ, USA, 14-19 September 2014.

15. Bulja, S.; Mirshekar-Syahkal, D.; Yazdanpanahi, M.; James, R.; Day, S.E.; Fernández, F.A. Liquid crystal based phase shifters in 60 GHz band. In Proceedings of the 3rd European Wireless Technology Conference, Paris, France, 27-28 September 2010; pp. 37-40.

16. Li, J.; Chu, D. Liquid crystal-based enclosed coplanar waveguide phase shifter for 54-66 ghz applications. Crystals 2019, 9, 650. [CrossRef]

17. Lapanik, V.; Sasnouski, G.; Timofeev, S.; Shepeleva, E.; Evtyushkin, G.; Haase, W. New highly anisotropic liquid crystal materials for high-frequency applications. Liq. Cryst. 2018, 45, 1242-1249. [CrossRef]

18. Economou, E.C.; Lovejoy, J.; Harward, I.; Nobles, J.E.; Kula, P.; Herman, J.; Glushchenko, A.; Celinski, Z. Liquid crystal based tunable spurline filters with notch frequencies at 50 and 85 GHz. Microw. Opt. Technol. Lett. 2018, 60, 672-679. [CrossRef]

19. Lane, S.; Brown, J.; Tremer, M.; Uber, C.; Gallagher, E.; Collins, S.; Benoit, M.; Miniscalco, W. Radiation testing of liquid crystal optical devices for space laser communication. Opt. Eng. 2009, 48, 114002. [CrossRef]

20. Kuyken, B.; Liu, X.P.; Osgood, R.M.; Baets, R.; Roelkens, G.; Green, W.M.J. Mid-infrared to telecom-band supercontinuum generation in highly nonlinear silicon-on-insulator wire waveguides. Opt. Express 2011, 19, 20172-20181. [CrossRef]

21. Zou, Y.; Chakravarty, S.; Chung, C.-J.; Xu, X.; Chen, R. Mid-infrared silicon photonic waveguides and devices [Invited]. Photonics Res. 2018, 6, 254. [CrossRef]

22. Soref, R. Mid-infrared photonics in silicon and germanium. Nat. Photonics 2010, 4, 495-497. [CrossRef]

23. Fang, Y.; Ge, Y.; Wang, C.; Zhang, H. Mid-Infrared Photonics using 2D materials: Status and challenges. Laser Photonics Rev. 2020, 14, 1900098. [CrossRef]

24. Rogalski, A. Infrared detectors: An overview. Infrared Phys. Technol. 2002, 43, 187-210. [CrossRef]

25. Brugioni, S.; Meucci, R. Liquid crystals in the mid-infrared region and their applications. Infrared Phys. Technol. 2004, 46, 17-21. [CrossRef]

26. Alves, F.D.P.; Karunasiri, G.; Hanson, N.; Byloos, M.; Liu, H.C.; Bezinger, A.; Buchanan, M. NIR, MWIR and LWIR quantum well infrared photodetector using interband and intersubband transitions. Infrared Phys. Technol. 2007, 50, 182-186. [CrossRef]

27. Saito, M.; Hayashi, K. Integration of liquid crystal elements for creating an infrared Lyot filter. Opt. Express 2013, 21, 11984-11993. [CrossRef]

28. Zhang, Y.; Song, P.; Xia, W.; Wang, J.; Zhou, C.; Zhang, H. A low-loss and high birefringence fluoride photonic crystal fiber in near infrared band. Optik 2019, 185, 772-776. [CrossRef]

29. Rave, E.; Roodenko, K.; Katzir, A. Infrared photonic crystal fiber. Appl. Phys. Lett. 2003, 83, 1912-1914. [CrossRef]

30. Du, X.; Li, Y.; Liu, Y.; Wang, F.; Luo, D. Electrically switchable bistable dual frequency liquid crystal light shutter with hyperreflection in near infrared. Liq. Cryst. 2019, 46, 1727-1733. [CrossRef]

31. Choi, G.J.; Jung, H.M.; Lee, S.H.; Gwag, J.S. Infrared shutter using cholesteric liquid crystal. Appl. Opt. 2016, 55, 4436-4440. [CrossRef]

32. Piecek, W.; Jaroszewicz, L.; Miszczyk, E.; Raszewski, Z.; Mrukiewicz, M.; Kula, P.; Jasek, K.; Perkowski, P.; NowinowskiKruszelnicki, E.; Zieliński, J.; et al. Mid-wave infrared liquid crystal shutter for breathalyzer applications. Opto-Electron. Rev. 2017, 25, 103-109. [CrossRef]

33. Xu, S.; Ren, H.; Wu, S.-T. Adaptive liquid lens actuated by liquid crystal pistons. Opt. Express 2012, 20, 28518-28523. [CrossRef]

34. Davis, S.; Rommel, S.; Johnson, S.; Farca, G.; Rebolledo, N.; Selwyn, S.; Anderson, M. Electro-optic steering of a laser beam. SPIE Newsroom 2011, 13. [CrossRef]

35. Frantz, J.; Myers, J.; Bekele, R.; Spillmann, C.; Naciri, J.; Kołacz, J.; Gotjen, H.; Shaw, L.; Sanghera, J.; Sodergren, B.; et al Non-Mechanical Beam Steering in the Mid-Wave Infrared. In Proceedings of the SPIE Defense + Commercial Sensing 2017 Conference, Anaheim, CA, USA, 9-13 April 2017; p. 101810X. 
36. McManamon, P.F.; Dorschner, T.A.; Corkum, D.L.; Friedman, L.J.; Hobbs, D.S.; Holz, M.; Liberman, S.; Nguyen, H.Q.; Resler, D.P.; Sharp, R.C.; et al. Optical phased array technology. Proc. IEEE 1996, 84, 268-298. [CrossRef]

37. Ren, H.; Wu, S.-T. Introduction to Adaptive Lenses; Wiley: Hoboken, NJ, USA, 2012.

38. Rogalski, A.; Chrzanowski, K. Infrared devices and techniques. Opto-Electron. Rev. 2002, 10, 111-136.

39. Chodorow, U.; Mazur, R.; Morawiak, P.; Herman, J.; Harmata, P.; Martyniuk, P. Switchable Fabry-Perot filter for mid-infrared radiation. Liq. Cryst. 2019, 46, 1877-1880. [CrossRef]

40. Węłłowska, D.; Czerwiński, M.; Kula, P.; Mrukiewicz, M.; Mazur, R.; Herman, J. Fast-response halogenated 4-alkyl-4"-cyano-pterphenyls as dual frequency addressing nematics. Fluid Phase Equilibria 2020, 522, 112770. [CrossRef]

41. Wąchała, A.; Pytlarczyk, M.; Kula, P. On the balance between nematic and smectic phases in $2^{\prime}, 3^{\prime}$-difluoro-4,4"-dialkyl-pterphenyls. Liq. Cryst. 2019, 46, 1558-1567. [CrossRef]

42. Kula, P.; Herman, J.; Pluczyk, S.; Harmata, P.; Mangelinckx, G.; Beeckman, J. Synthesis and mesomorphic properties of laterally substituted 4,4"' -dialkyl-p-quaterphenyls. Liq. Cryst. 2014, 41, 503-513. [CrossRef]

43. Herman, J.; Harmata, P.; Strzeżysz, O.; Czerwiński, M.; Urban, S.; Kula, P. Synthesis and properties of chosen 4-butyl-phenyltolane derivatives-On the influence of core substitution on birefringence, mesomorphic and dielectric properties. J. Mol. Liq. 2018, 267, 511-519. [CrossRef]

44. Dziaduszek, J.; Kula, P.; Dabrowski, R.; Drzewiński, W.; Garbat, K.; Urban, S.; Gauza, S. General synthesis method of alkyl-alkoxy multi-fluorotolanes for negative high birefringence nematic mixtures. Liq. Cryst. 2012, 39, 239-247. [CrossRef]

45. Dabrowski, R.; Dziaduszek, J.; Garbat, K.; Urban, S.; Filipowicz, M.; Herman, J.; Czerwiński, M.; Harmata, P. Nematic compounds and mixtures with high negative dielectric anisotropy. Liq. Cryst. 2017, 44, 1534-1548. [CrossRef]

46. Ziobro, D.; Dziaduszek, J.; Filipowicz, M.; Dąbrowski, R.; Czub, J.; Urban, S. Synthesis of fluorosubstituted three ring esters and their dielectric properties. Mol. Cryst. Liq. Cryst. 2009, 502, 258-271. [CrossRef]

47. Wegłowska, D.; Kula, P.; Herman, J. High birefringence bistolane liquid crystals: Synthesis and properties. RSC Adv. 2015, 6, 403-408. [CrossRef]

48. Urbańska, M.; Perkowski, P.; Szala, M. Synthesis and properties of antiferroelectric and/or ferroelectric compounds with the - $\mathrm{CH} 2 \mathrm{O}$ group close to chirality centre. Liq. Cryst. 2019, 46, 2245-2255. [CrossRef]

49. Herman, J.; Dmochowska, E.; Pytlarczyk, M.; Harmata, P. Synthesis and mesomorphism of tetrafluoro substituted 4-cyano oligophenyls. Liq. Cryst. 2019, 46, 1666-1671. [CrossRef]

50. Herman, J.; Kula, P. Design of new super-high birefringent isothiocyanato bistolanes—synthesis and properties. Liq. Cryst. 2017, 44, 1462-1467. [CrossRef]

51. Szczuciński, Ł.; Dabrowski, R.; Urban, S.; Garbat, K.; Filipowicz, M.; Dziaduszek, J.; Czerwiński, M. Synthesis, mesogenic and dielectric properties of fluorosubstituted isothiocyanatoterphenyls. Liq. Cryst. 2015, 42, 1706-1729. [CrossRef]

52. Hird, M. Fluorinated liquid crystals_Properties and applications. Chem. Soc. Rev. 2007, 36, 2070-2095. [CrossRef]

53. Kula, P.; Spadło, A.; Dziaduszek, J.; Filipowicz, M.; Dąbrowski, R.; Czub, J.; Urban, S. Mesomorphic, dielectric, and optical properties of fluorosubstituted biphenyls, terphenyls, and quaterphenyls. Opto-Electron. Rev. 2008, 16, 379-385. [CrossRef]

54. Mrukiewicz, M.; Perkowski, P.; Urbańska, M.; Węłowska, D.; Piecek, W. Electrical conductivity of ion-doped fluoro substituted liquid crystal compounds for application in the dynamic light scattering effect. J. Mol. Liq. 2020, 317, 113810. [CrossRef]

55. Pytlarczyk, M.; Dmochowska, E.; Czerwiński, M.; Herman, J. Effect of lateral substitution by chlorine and fluorine atoms of 4-alkyl-p-terphenyls on mesomorphic behaviour. J. Mol. Liq. 2019, 292, 111379. [CrossRef]

56. Wu, S.-T.; Cox, R.J. Potential infrared liquid crystals. Liq. Cryst. 1989, 5, 1415-1424. [CrossRef]

57. Harmata, P.; Herman, J.; Kula, P. Liquid crystals for IR: Part II synthesis and properties of perfluoroalkyl- or perfluoroalkoxyterminated tolanes. Liq. Cryst. 2019, 47, 2144-2160. [CrossRef]

58. Harmata, P.; Herman, J.; Kula, P. Liquid crystals for IR: Part I—synthesis and properties of perfluoroalkyl or perfluoroalkoxy terminated oligophenyls. Liq. Cryst. 2019, 47, 2122-2143. [CrossRef]

59. Kula, P.; Czerwinski, M.; Herman, J.; Harmata, P. Liquid crystals for IR: Part III-Bi- and multicomponent mixtures based on perfluoroalkyl or perfluoroalkoxy terminated oligophenyls and tolanes. Liq. Cryst. 2020, 47, 2161-2170. [CrossRef]

60. Hu, M.; An, Z.; Li, J.; Chen, H.; Peng, F.; Wu, S.-T.; Wang, X.; Li, M. Low mid-infrared absorption tolane liquid crystals terminated by 2,2-difluorovinyloxyl: Synthesis, characterization and properties. J. Mater. Chem. C 2016, 4, 4939-4945. [CrossRef]

61. Peng, F.; Chen, Y.; Wu, S.-T.; Tripathi, S.; Twieg, R. Low loss liquid crystals for infrared applications. Liq. Cryst. 2014, 41, 1545-1552. [CrossRef]

62. Chen, Y.; Xianyu, H.; Sun, J.; Kula, P.; Dabrowski, R.; Tripathi, S.; Twieg, R.; Wu, S.-T. Low absorption liquid crystals for mid-wave infrared applications. Opt. Express 2011, 19, 10843-10848. [CrossRef] [PubMed]

63. Hu, M.; An, Z.; Li, J.; Mo, L.; Yang, Z.; Li, J.; Che, Z.; Yang, X. Tolane liquid crystals bearing fluorinated terminal group and their mid-wave infrared properties. Liq. Cryst. 2014, 41, 1696-1702. [CrossRef]

64. Szaniawska, K.; Nasilowski, T.; Woliński, T.R.; Thienpont, H. Tunable properties of light propagation in photonic liquid crystal fibers. Opto-Electron. Rev. 2006, 14, 339-343. [CrossRef]

65. Wolinski, T.R.; Ertman, S.; Lesiak, P.; Domanski, A.W.; Czapla, A.; Dabrowski, R.; Nowinowski-Kruszelnicki, E.; Wojcik, J. Photonic liquid crystal fibers-a new challenge for fiber optics and liquid crystals photonics. Opto-Electron. Rev. 2006, 14, 329-334. [CrossRef] 
66. Wolinski, T.R.; Szaniawska, K.; Bondarczuk, K.; Lesiak, P.; Domanski, A.W.; Dabrowski, R.; Nowinowski-Kruszelnicki, E.; Wojcik, J. Propagation properties of photonic crystal fibers filled with nematic liquid crystals. Opto-Electron. Rev. 2005, 13, 177-182.

67. Kedzierski, J.; Garbat, K.; Raszewski, Z.; Kojdecki, M.A.; Kowiorski, K.; Jaroszewicz, L.R.; Miszczyk, E.; Dabrowski, R.; Zielinski, J.; Piecek, W. Optical properties of a liquid crystal with small ordinary and extraordinary refractive indices and small optical anisotropy. Opto-Electron. Rev. 2014, 22, 162-165. [CrossRef]

68. Sage, I.; Chaplin, D. Low ri liquid-crystals for integrated-optics. Electron. Lett. 1987, 23, 1192-1193. [CrossRef]

69. Haller, I. Thermodynamic and static properties of liquid crystals. Prog. Solid State Chem. 1975, 10, 103-118. [CrossRef]

70. Zywucki, B.J.; Kuczynski, W. The orientational order in nematic liquid crystals from birefringence measurements. IEEE Trans. Dielectr. Electr. Insul. 2001, 8, 512-515. [CrossRef]

71. Malitson, I.H. Interspecimen comparison of the refractive index of fused silica. J. Opt. Soc. Am. 1965, 55, 1205-1209. [CrossRef]

72. Wang, Z.-Y.; Qiu, Q.; Shi, S.-J. Temperature dependence of the refractive index of optical fibers. Chin. Phys. B 2014, $23,034201$. [CrossRef]

73. Rodney, W.S.; Spindler, R.J. Index of refraction of fused quartz glass for ultraviolet, visible, and infrared wavelengths. J. Opt. Soc. Am. 1954, 44, 677-679. [CrossRef]

74. Wray, J.H.; Neu, J.T. Refractive index of several glasses as a function of wavelength and temperature. J. Opt. Soc. Am. 1969, 59, 774-776. [CrossRef] 